\title{
Correction to: Overcoming Historical Barriers: Enhancing Positive Perceptions of Medical Research Among African Americans Through a Conference-Based Workshop
}

LaPrincess C. Brewer, MD, MPH ${ }^{1,2}$, Maarya Pasha, MD³, Pernessa Seele, $L H D^{4}$, Sumedha Penheiter, $P h D^{2}$, Richard White, $M D^{5}$, Floyd Willis, $M D^{6}$, Monica Albertie, $M H A^{7}$, Sarah $M$. Jenkins, $M S^{8}$, and Christopher Pullins, $M D^{9}$

'Department of Cardiovascular Medicine, Mayo Clinic College of Medicine, Rochester, MN, USA; ${ }^{2}$ Center for Health Equity and Community Engagement Research, Mayo Clinic, Rochester, MN, USA; ${ }^{3}$ Department of General Internal Medicine, Mayo Clinic College of Medicine,

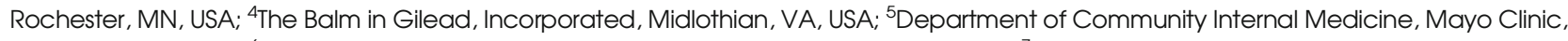
Jacksonville, FL, USA; ${ }^{6}$ Department of Family Medicine, Mayo Clinic, Jacksonville, FL, USA; ${ }^{7}$ Center for Health Equity and Community Engagement Research, Mayo Clinic, Jacksonville, FL, USA; ${ }^{8}$ Department of Health Sciences Research, Mayo Clinic, Rochester, MN, USA; ${ }^{9}$ Department of Family Medicine, Mayo Clinic Arizona, Scottsdale, AZ, USA.

$\mathrm{J}$ Gen Intern Med

DOI: $10.1007 / \mathrm{s} 11606-021-07036-5$

( ) Society of General Internal Medicine 2021

C ORRECTION TO J GEN INTERN MED

https://doi.org/10.1007/s11606-021-06736-2

This paper has been changed online to Open Access.

Corresponding Author: LaPrincess C. Brewer, MD, MPH; Center for Health Equity and Community Engagement Research, Mayo Clinic, Rochester, MN, USA (e-mail: Brewer.LaPrincess@mayo.edu).

Publisher's Note: Springer Nature remains neutral with regard to jurisdictional claims in published maps and institutional affiliations.

The online version of the original article can be found at https://doi.org/10. 1007/s11606-021-06736-2 